\title{
Ganho Genético na Cultura da Soja
}

\section{Genetic Gain in Soybean Crop}

\author{
Anderson Paranzini Faria ${ }^{1}$; Nelson da Silva Fonseca Júnior ${ }^{2}$; \\ Deonisio Destro ${ }^{3}$; Ricardo Tadeu de Faria ${ }^{3}$
}

\section{Resumo}

A seleção de genótipos de soja com elevada produtividade de grãos e capacidade de adaptação ambiental é o principal objetivo dos programas de melhoramento genético. Para verificar se o ganho genético por meio de melhoramento da cultura da soja está sendo alcançado é importante que cada programa de melhoramento faça, frequentemente, uma auto-avaliação no sentido de verificar se houve progresso efetivo e se determinada condição de cultivo foi privilegiada pelo melhoramento e corrigir eventuais distorções de metas. Para isso é necessário a utilização de métodos que quantifiquem o avanço genético. A possibilidade de predição dos ganhos obtidos por seleção constitui-se em uma das principais contribuições para o melhoramento. Desta forma, torna-se possível orientar de maneira mais efetiva os programas de melhoramento, predizer o sucesso do esquema de seleção adotado e determinar, de forma científica, quais as técnicas que podem ser mais eficazes.

Palavras-chave: Glycine Max, melhoramento, adaptabilidade

\begin{abstract}
The selection of genotypes of soybean with high grain yield and high capacity of environment adaptation are the objectives of the genetic improvement programs. To verify if the genetic gain through of the breeding of the soybean crop is being reached it is necessary that, frequently, each improvement program makes an auto-evaluation to verify if there has been effective progress, if a certain culture condition was privileged by the breeding and to correct eventual distortions of goals. To have significant advances the breeding programs have to evaluate their efficiency and it is necessary to use methods that quantify the genetic advances. The possibility of prediction of the gains obtained by selection consists in one of the main contributions for the breeding, becoming possible to guide in a more effective manner the breeding program, to predict the success of the adopted selection method and to determine, scientifically, which techniques can be more efficient.
\end{abstract}

Keywords: Glycine max, improvement, adaptability

1 Eng. Agrônomo, Mestrando em Agronomia na Universidade Estadual de Londrina - Bolsista da CAPES.

2 Pesquisador Doutor no IAPAR - Área de concentração - Melhoramento e Genética Vegetal

3 Professor Doutor no Depto. de Agronomia, Universidade Estadual de Londrina.

* Autor para correspondência 


\section{Introdução e Revisão}

A soja (Glycine max (L.) Merrill) é reconhecida como uma das mais antigas plantas cultivadas no planeta. As primeiras citações do grão apareceram no período entre 2.883 e 2.838 a.C., quando a soja era considerada um grão sagrado, como o arroz, o trigo, a cevada e o milheto, por sua importância na dieta alimentar dos chineses. Porém, alguns autores acreditam que as referências à soja são ainda mais antigas (EMPRESA BRASILEIRA DE PESQUISA AGROPECUÁRIA, 2005).

Nos seus primórdios a soja era de hábito rasteiro, sendo encontrada na costa leste de Ásia, principalmente na China. Sua evolução ocorreu de plantas oriundas de cruzamentos naturais entre duas espécies de soja selvagem, que foram domesticadas e melhoradas por cientistas da antiga China (EMPRESA BRASILEIRA DE PESQUISA AGROPECUÁRIA, 2005).

Os progressos genéticos referem-se às alterações observadas nas características de interesse durante um ciclo de seleção, com a recombinação e multiplicação das unidades selecionadas. Tais modificações ocorrerão em magnitude e sentido variados, dependendo da estratégia e dos critérios de seleção adotados. Assim, uma das atribuições mais importantes do melhorista de plantas é identificar critérios de seleção capazes de promover alterações, no sentido desejado, nas características de interesse dentro de um programa de melhoramento (REIS et al., 2004).

De acordo com Costa et al. (2004) os programas de melhoramento genético da cultura são essenciais para atender à crescente demanda por maiores produções, possibilitando aumento de variabilidade e conseqüente ampliação da base genética e a seleção dos melhores genótipos de uma população capazes de superar os patamares de produtividade de grãos.

O conhecimento do comportamento dos diferentes ciclos de maturação ajuda no planejamento das épocas de semeadura e colheita, possibilitando ao produtor enfrentar com maior grau de sucesso as variações do ambiente (doenças e pragas, chuvas excessivas, secas, geadas, efeitos do fotoperíodo) (ROCHA; VELLO, 1999).

O progresso genético direcionado em qualquer espécie está associado à existência de variabilidade genética, à seleção natural e/ou artificial e ao ajuste dos genótipos aos ambientes existentes. Comprovada a presença da variabilidade genética, a seleção assume importância no progresso genético (REIS et al., 2004).

Segundo Rossmann (2001), a obtenção de estimativas de parâmetros genéticos e fenotípicos, tais como herdabilidades, correlações genéticas e fenotípicas e ganhos esperados com seleção, têm importância em programas de melhoramento genético, pois possibilitam a tomada de decisões relacionadas com a escolha do método mais apropriado, os caracteres que devem ser selecionados em etapas iniciais e avançadas de um programa e também o peso que deve ser atribuído a cada caráter, separadamente ou em conjunto.

Contudo, selecionar progênies superiores não é tarefa fácil uma vez que os caracteres de importância, em sua maioria quantitativos, apresentam comportamento complexo por serem influenciados pelo ambiente e estarem inter-relacionados de tal forma que a seleção de um provoca uma série de mudanças em outros (CRUZ; REGAZZI, 1997).

Fonseca Júnior (1997), estudando os diferentes métodos para se estimar ganho genético, no período de 1977 a 1995, em feijão, concluiu que o desafio dos métodos de estimativas de ganho genético é obter médias de genótipos o mais livre possível do efeito ambiental.

Para a obtenção de genótipos superiores, é necessária a reunião de uma série de atributos favoráveis que confiram produtividade de grãos mais elevada e satisfaçam as exigências do mercado. Com isso, a seleção baseada em uma ou poucas características mostra-se inadequada, conduzindo a um produto final superior apenas em relação aos caracteres selecionados (CRUZ; REGAZZI, 1997). 
Vencovsky e Barriga (1992) relatam que não basta apenas detectar a presença de interações, devendose também considerar a sua natureza. Assim, a interação genótipo $\mathrm{x}$ ambiente pode ser simples (não causa mudanças na classificação dos genótipos entre ambientes) e complexa (altera a classificação dos genótipos entre ambientes). A interação simples indica a presença de genótipos adaptados a uma ampla faixa de ambientes; assim, a recomendação de cultivares pode ser feita de forma generalizada. A interação complexa indica a presença de material adaptado a ambientes particulares, tornando a recomendação restrita a ambientes específicos (RAMALHO; SANTOS; ZIMMERMANN, 1993).

A interação genótipo $\mathrm{x}$ ambiente tem sido estudada em soja com o objetivo de estimar os seguintes efeitos: efeitos envolvendo genótipos $\mathrm{x}$ locais (SOLDINI, 1993), genótipos $\mathrm{x}$ anos (BILLORE; JOSHI, 1997; GIECO, 1997), genótipos $x$ locais $x$ anos (TOLEDO et al., 1990; ALLIPRANDINI et al., 1994; LAÍNEZ-MEJÍA, 1996), genótipos $x$ épocas de semeadura (MORAES et al., 1997; RAUT et al., 1997), genótipos x anos x épocas de semeadura (GALVÃO, 1994) e genótipos $\mathrm{x}$ locais $\mathrm{x}$ anos x épocas de semeadura (ARANTES, 1979; AKHTER; SNELLER, 1996).

Alliprandini et al. (1993) confirmam tal importância ao avaliar o comportamento de genótipos divididos em três ciclos de maturação (precoce, semi-precoce e médio). A interação significativa obtida para ciclos de maturação x locais x anos indica que, para determinada combinação entre ano e local, existe um ciclo de maturação com maior produtividade de grãos.

Um fator fundamental no processo de obtenção de linhagens de soja melhoradas consiste na avaliação dos genótipos em ensaios, quando fica caracterizado seu desempenho em face de cultivares conhecidas com alto potencial produtivo de grãos e ampla adaptação. As técnicas de avaliação do progresso genético que utilizam informações obtidas em testes obrigatórios de linhagens nos programas permitem o acompanhamento do ganho genético das linhagens obtidas ao longo dos anos de maneira econômica e eficiente (VENCOVSKY et al., 1986; FERNANDES, 1988). O acompanhamento desse progresso fornece subsídios importantes para a avaliação e o planejamento das atividades de melhoramento.

O esforço do melhoramento foi concentrado na obtenção de cultivares produtivos e com ampla faixa de adaptação, sem relegar a um segundo plano os objetivos específicos que visam sanar problemas locais ou regionais (ALLIPRANDINI, 1993).

A seleção objetiva acumular alelos favoráveis à característica de interesse em determinada população e é um processo vinculado a uma constante e permanente renovação (REIS et al., 2004).

Portanto, esta revisão tem por objetivo apresentar os métodos para estimação de ganho genético nos programas de melhoramento para evidenciar as suas eficiências nos programas de melhoramento genético da soja.

\section{Métodos para Estimação de Ganho Genético}

\section{Método Direto (MD)}

Este método consiste em comparar em um mesmo ano agrícola e em vários ambientes, genótipos lançados em diferentes anos. Esta metodologia foi utilizada em diferentes espécies, entre elas milho (CARDWELL, 1982; DUVICK, 1992), soja (WILCOX et al., 1979; SALADO-NAVARRO; SINCLAR; HINSON, 1993), trevo branco (WOODFIELD; CARADUS, 1994), alfafa (HOLLAND; BINGHAM, 1994), cevada (BULMAN; MATHER; SMITH, 1993), trigo (BERZONSKY; LAFEVER, 1993; NEDEL, 1994; PELTONEN-SAINIO; PELTONEN, 1994; LILL; PURCHASE, 1995).

Esta metodologia apresenta alguns inconvenientes, pois exige ensaios específicos para esta estimação de ganho, requerendo a manutenção cuidadosa dos 
genótipos primitivos e rigorosa observação quanto à uniformização da origem (local e ano) de suas sementes. Há, no entanto, uma limitação a este método, que teoricamente seria o mais próximo do ideal: a aceitação da hipótese de que nem o ambiente, nem as exigências do mercado, nem os objetivos do programa de melhoramento se alteraram ao longo do tempo, tornando válida a comparação entre genótipos lançados em diferentes anos.

Fator limitante para o sucesso dessa metodologia é o efeito do ano e a interação genótipos por anos, que podem mascarar a efetiva contribuição dos genótipos novos. Aparentemente, este método pode ser de maior utilidade na estimação do progresso genético obtido em características com maior herdabilidade e menos sujeitas às influências ambientais, como é o caso das características teor de óleo e proteína em milho, que tem padrão de ganho genético crescente, e menos errático que a utilização da massa de 100 grãos (DUDLEY; LAMBERT, 1992).

\section{Método com Ensaios Multilocais}

\section{A. Método Original (MO)}

Essa metodologia é a que utiliza os ensaios da rede de competição de genótipos, cujos resultados embasam a indicação de novos cultivares, para estabelecer estimativas de ganho genético. Estes ensaios regionais são compostos por genótipos que podem ser classificados em função de sua origem: a) genótipos novos: são os que participam pela primeira vez nos ensaios; b) genótipos comuns: aqueles que foram selecionados no ano anterior e que permaneceram em teste no ano seguinte para avaliação e c) genótipos padrões ou testemunhas: normalmente enquadram-se no grupo dos genótipos comuns, pois permanecem nos ensaios por mais de dois anos consecutivos.

Vencovsky et al. (1988), utilizando os dados de produtividade de grãos de milho dos ensaios nacionais, propuseram um método, pelo qual a estimativa do ganho genético é obtida pelo contraste entre a média de todos os tratamentos de um dado ano e a do ano anterior. Deste contraste, subtrai-se o efeito de ano, estimado pela diferença entre a média do grupo de genótipos comuns nesses dois anos consecutivos.

Aplicações desse método em soja, milho, feijão, algodão e outras culturas fornecem informações importantes sobre o ganho genético em anos consecutivos (VENCOVSKY et al., 1988; TOLEDO et al., 1990; ALLIPRANDINI et al., 1993; ABREU et al., 1994; ARAÚJO, 1995; CARVALHO et al., 1997; FERNANDES; FRAZON, 1997; FONSECA JÚNIOR, 1997; AMORIM NETO et al., 1998; ARIAS; RAMALHO, 1998; BRESEGHELLO; RANGEL; MORAIS, 1999; SOARES et al., 1999; ATROCH; NUNES, 2000; BARBOSA NETO et al., 2000; RIBEIRO; POSSEBON; STORCK, 2003).

\section{B. Método Original com Ponderação (MOP)}

Fernandes (1988), trabalhando com dados do ensaio nacional de milho, propôs uma modificação no método original (VO) para estimar o desvio ambiental médio anual por local, utilizando o método dos quadrados mínimos ponderados (QMP). Esta modificação visava: a) evitar a perda de informações, pois no método original, ao se efetuar a estimativa do desvio genético médio, as médias dos tratamentos dos anos intermediários se cancelavam, restando apenas o primeiro e o último ano para o cálculo da estimativa; b) levar em consideração o número de observações de cada genótipo e c) eliminar a correlação dos erros experimentais entre anos consecutivos. Rodrigues (1990) estendeu a metodologia anterior para os estudos de ganho genético em sorgo no Brasil, fornecendo embasamento para as deduções das expressões de ganho genético médio anual e seu desvio por local ou ensaio analisado. Alliprandini et al. (1993) estimaram o ganho genético médio anual em soja no estado do Paraná, empregando esta mesma metodologia com a ponderação proposta por Fernandes (1988). 
C. Métodos que Utilizam um Genótipo Referência

Os experimentos regionais são compostos normalmente por genótipos novos, por genótipos comuns que integram pelo segundo ano consecutivo estes experimentos, e pelas testemunhas. Os genótipos em teste podem ter dois destinos: ou são descartados ou são selecionados. Eventualmente, um determinado genótipo permanece como testemunha ao longo de todos os anos testados e pode ser usado como referencial para estimativa de ganho genético como utilizado por Abreu et al. (1994), Eyhérabide, Damilano e Colazo (1994), McCaig e Clarke (1995), Bell et al. (1995), McCaig e DePauw (1995); Córdova, Barreto e Crossa (1996). Basicamente estes autores utilizaram-se de regressões lineares ou de análise de covariância em seus trabalhos contendo testemunha comum.

\section{Método da Regressão com Dados Originais (RO)}

São estabelecidas duas equações de regressão linear, uma para o cultivar padrão e a segunda para os demais genótipos. A variável dependente representa as médias originais da produtividade de grãos e a variável independente corresponde aos anos de experimentação. Em seguida, são comparados os coeficientes angulares (b) de ambas regressões mediante a subtração ( $b$ de genótipos menos $b$ da testemunha) e obtêm-se a estimativa do ganho genético médio anual em kg.ha ${ }^{-1}$, conforme efetuado por Abreu et al. (1994). Ressalte-se que esta metodologia (RO) é altamente dependente do efeito do ano agrícola, visto que apenas um genótipo (a testemunha comum), é utilizado para indicar as variações ambientais, que ocorrem nos diferentes anos.

\section{Testemunha como Fator de Correção}

Outro modo de estimação de progresso genético, mediante o auxílio de testemunha comum em todos os experimentos, é utilizando a sua produtividade como covariável da produtividade dos demais genótipos, obtendo-se médias ajustadas, livres do efeito ambiental, à semelhança da correção da produtividade de grãos em função do número de plantas na parcela. Com as médias anuais ajustadas efetua-se estudo de regressão em função dos anos e pelo coeficiente angular (b) estima-se o ganho genético médio anual, como utilizado por Eyhérabide, Damilano e Colazo (1994).

Córdova, Barreto e Crossa (1996) alertam para os cuidados na escolha da testemunha referencial, que deve corresponder às expectativas dos agricultores e melhoristas, apresentando desempenho estável e com produtividade de grãos em nível satisfatório.

\section{Resultados com Soja}

$\mathrm{Na}$ avaliação do programa de melhoramento genético em soja, Alliprandini et al. (1993) utilizaram o método descrito por Vencovsky et al. (1988) e modificado por Fernandes (1988). Estes autores obtiveram resultados médios anuais, em produtividade de grãos, da ordem de $0,89 \%$ no grupo precoce, de 0,38\% no grupo semi-precoce e de $-0,28 \%$ no grupo médio de maturação. Martin e Geraldi (2002) demonstram resultados de ganho genético, em soja, de $4 \%$ obtidos, durante o programa de melhoramento.Toledo et al. (1990), analisando a eficiência do programa de melhoramento em soja no Estado do Paraná no período de 1981 a 1986 obteve ganho genético de $1,8 \%$ no grupo precoce e $1,3 \%$ para genótipos do grupo semi-precoce.

Comparando quatro estratégias de seleção, Reis et al. (2004) visando estimar ganho genético em soja, obtiveram resultados que indicaram que a estratégia de seleção individual teve maior expectativa de progresso genético entre as estratégias adotadas. Diferentes critérios de seleção foram utilizados por Costa et al. (2004), avaliando 1.200 genótipos de soja, obtendo as maiores estimativas de ganhos pela seleção direta. Porém, os índices apresentaram-se mais adequados para a seleção dos genótipos superiores por registrarem maiores ganhos totais, distribuídos entre todos os caracteres avaliados. 


\section{Considerações Finais}

Os métodos que estimam o ganho genético servem para analisar a eficácia do programa de melhoramento. Desta forma, as estratégias podem ser ajustadas para a obtenção de maior eficácia no programa de melhoramento.

\section{Agradecimentos}

Ao CNPq (Conselho Nacional de Desenvolvimento Científico e Tecnológico) e à CAPES (Coordenação de Aperfeiçoamento de Pessoal de Nível Superior) pelo apoio financeiro.

\section{Referências}

ABREU, A. F. B.; RAMALHO, M. A. P.; SANTOS, J. B.; MARTINS, L. A. Progresso do melhoramento genético do feijoeiro nas décadas de setenta e oitenta nas regiões Sul e alto Paranaíba em Minas Gerais. Pesquisa Agropecuária Brasileira, Brasília, v.29, n.1, p.105-12, 1994.

AKHTER, M; SNELLER, C. H. Genotype x planting date interaction and selection of early maturing soybean genotypes. Crop Science, Madison, v.36, n.4, p.883-889, jul./aug. 1996.

ALLIPRANDINI, L. F.; TOLEDO, J. F. F.; FONSECA JUNIOR, N. S.; KIIHL, R. A. S. Ganho genético em soja no Estado do Paraná, via melhoramento no período de 1985/ 86 a 1989/90. Pesquisa Agropecuária Brasileira, Brasília, v.28, n.4, p.489-497, 1993.

ALLIPRANDINI, L. F.; TOLEDO, J. F. F.; FONSECA JUNIOR, N. F.; ALMEIDA, L. A.; KIIHL, R. A. S. Efeitos da interação genótipo $\mathrm{x}$ ambiente sobre a produtividade da soja no Estado do Paraná. Pesquisa Agropecuária Brasileira, Brasília, v.29, n.9, p.1433-1444, 1994.

AMORIM NETO, S.; ANDRADE, W.E. B.; COSTA, R. A. da. Aumento da produtividade de arroz irrigado no Estado do Rio de Janeiro de 1981/82 a 1991/92. Pesquisa Agropecuária Brasileira, Brasília, v.33, p.369-374, 1998.

ARANTES, N. E. Interação genótipo x ambiente e estudo de alternativas para seleção de variedades de soja (Glycine max (L.) Merrill), com base em testes regionais. 1979. Dissertação (Mestrado em Agronomia)-Universidade Federal de Viçosa, Viçosa.

ARAÚJO, J. S. Ganhos genéticos obtidos em híbridos e variedades de milho representativos de três décadas de melhoramento no Brasil. 1995. Dissertação (Mestrado) Universidade Federal de Lavras, Lavras.

ARIAS, E. R. A.; RAMALHO, M. A. P. Progresso genético em milho no Estado do Mato Grosso do Sul, no período de 1986/87 a 1993/94. Pesquisa Agropecuária Brasileira, Brasilia, v.33,p.1534-1538, 1998.

ATROCH, A. L.; NUNES, G. H. S. Progresso genético em arroz de várzea úmida no Estado do Amapá. Pesquisa Agropecuária Brasileira, Brasília, v.35, n.4, p.767-771, 2000.

BARBOSA NETO, J. F.; MATIELLO, R. R.; CARVALHO, F. I. F.; OLIVEIRA, J. M. S.; PEGORARO, D. G.; SCHNEIDER, F.; SORDI, M. H. B.; VACARO, E. Progresso genético no melhoramento da aveia-branca no Sul do Brasil. Pesquisa Agropecuária Brasileira, Brasília, v.35, n.8, p.1605-1612, 2000.

BELL, M. A.; FISHER, R. A.; BYERLEE, D.; SAYRE, K. Genetic and agronomic contributions to yield gains: a case of study for wheat. Field Crops Research, Amsterdam, v.44, n.1, p.55-65, 1995.

BERZONSKY, W. A.; LAFEVER, H. N. Progress m Ohio soft red winter wheat breeding: grain yield and agronomic traits of cultivars released from 1871 to 1987. Crop Science, Madison, v.33, n.6, p.1382-1386, 1993.

BILLORE, S. D.; JOSHI, O. P. Genotypical variability for yield and quality in Glycine $\max ($ L.) Merrill. Soybean Genetics Newsletter, Ames, v.24, p.88-91, 1997.

BRESEGHELLO, F.; RANGEL, P. H. N.; MORAIS, O. P. Ganho de produtividade pelo melhoramento genético do arroz irrigado no Nordeste do Brasil. Pesquisa Agropecuária Brasileira, Brasília, v.34, n.3, p.399-407, 1999.

BULMAN, P.; MATHER, D. E.; SMITH, D. L. Genetic improvement of spring barley cultivars grown in eastern Canada from 1910 to 1988. Euphytica, Wageningen, v.71, n.1, p.35-48, 1993.

CARDWELL, V. B. Fifty years of Minnesota com production: sources of yield increase. Agronomy Journal, Madison, v.74, n.6, p.984-990, 1982.

CARVALHO, L. P.; BARBOSA, M. H. P.; COSTA, J. N.; FARIAS, F. J. C.; SANTANA, J. C. F.; ANDRADE, F. P. Progresso genético do algodoeiro herbáceo no Nordeste. Pesquisa Agropecuária Brasileira, Brasília, v.32, n.3, p.283-291, 1997.

CÓRDOVA, H. S.; BARRETO, H. J.; CROSSA, J. Hybrid development in central América: reliability of yield gains against a regional check. Maydica, Bergamo, v.41, n.4, p.349-353, 1996. 
COSTA, M. M.; MAURO, A. O. D.; UNÊDA-TREVISOLI, S. H.; ARRIEL, N. H. C.; BÁRBARO, I. M.; MUNIZ, F. R. S. Ganho genético por diferentes critérios de seleção em populações segregantes de soja. Pesquisa Agropecuária Brasileira, Brasília, v.39, n.11, p.1095-1102, 2004.

CRUZ, C. D.; REGAZZI, A. J. Modelos biométricos aplicados ao melhoramento genético. Viçosa: UFV, 1997.

DUDLEY, J. W.; LAMBERT, R. J. Ninety generations of selection for oil and protein in maize. Maydica, Bergamo, v.37, n.1, p.81-87, 1992.

DUVICK, D. N. Genetic contributions to advances in yield of U.S. maize. Maydica, Bergamo, v.37, n.1, p.69-79, 1992.

EMPRESA BRASILEIRA DE PESQUISA AGROPECUÁRIA - EMBRAPA SOJA. Soja. Disponível em: $<$ http://www.cnpso.embrapa.br $>$. Acesso em: 30 abr. 2005.

EYHÉRABIDE, G. H.; DAMILANO, A. L.; COLAZO, J. C. Genetic gain for grain yield of maize in Argentina. Maydica, Bergamo, v.39, n.3, p.207-211, 1994.

FERNANDES, J. S. C. Estabilidade ambiental de cultivares de milho (Zea mays L.) na região Centro Sul do Brasil. 1988. Tese (Mestrado) - Escola Superior de Agricultura "Luiz de Queiroz"/USP, Piracicaba.

FERNANDES, J. S. C.; FRAZON, J. F. Thirty years of genetic progress in maize (Zea mays L.) in a tropical environment. Maydica, Bergamo, v.42, n.1, p.21-27, 1997.

FONSECA JÚNIOR, N. S. Progresso genético na cultura do feijão no Estado do Paraná para o período de 1977 a 1995. 1997. Tese (Doutorado) - Escola Superior de Agricultura “Luiz de Queiroz”, Piracicaba.

GALVÃO, E. R. Adaptabilidade e estabilidade de comportamento de nove genótipos de soja (Glycine max (L.) Merrill) em Ponta Porã, Mato Grosso do Sul. 1994. Dissertação (Mestrado em Agronomia) - Universidade Federal de Viçosa, Viçosa.

GIECO, J. O. Interação genótipos $x$ ambientes $e$ implicações para o melhoramento da soja. 1997. Dissertação (Mestrado em Genética e Melhoramento de Plantas) - Escola Superior de Agricultura "Luiz de Queiroz"/USP, Piracicaba.

HOLLAND, J. B; BINGHAM, E. T. Genetic improvement for yield and fertility of alfafa cultivars representing different eras of breeding. Crop Science, Madison, v.34, n.4, p.953-957, 1994.

LAÍNEZ-MEJÍA, J. R. Implicações da interação genótipos $x$ ambientes na seleção de progênies de soja com ênfase nas produtividades de grãos e óleo. 1996. Tese (Doutorado em Genética e Melhoramento de Plantas)- Escola Superior de Agricultura “Luiz de Queiroz”/USP, Piracicaba.
LILL, D.; PURCHASE, J. L. Directions in breeding for winter wheat yield and quality in South Africa from 1930 do 1990. Euphytica, Wageningen, v.82, n.1, p.79-87, 1995.

MARTIN, S. K. S.; GERALDI, I. O. Comparison of three procedures for early generation testing of soybean. Crop Science, Madison, v.42, p.705-709, 2002.

McCAIG, T. N.; CLARKE, J. M. Breeding durum wheat in western Canada: historical trends in yield and related variables. Canadian Journal of Plant Science, Ottawa, v.75, n.1, p.55-60, 1995.

McCAIG, T. N.; DePAUW, R. M. Breeding hard red spring wheat in western Canada: historical trends in yield and related variables. Canadian Journal of Plant Science, Ottawa, v.75, p.387-393, 1995.

MORAES, L. K.; PINHEIRO, J. B.; COELHO, S. G.; ROSA, S. R.A.; REIS, A. J. S. Interação de cultivares de soja com épocas de semeadura. In: CONGRESSO NACIONAL DE GENÉTICA, 43., Goiânia, 1997. Anais... Goiânia: SBG, 1997. p.166.

NEDEL, J. L. Progresso genético no rendimento de grãos de cultivares de trigo lançadas para cultivo entre $1940 \mathrm{e}$ 1992. Pesquisa Agropecuária Brasileira, Brasília, v.29, n.10, p.1565-1570,1994.

PELTONEN-SAINIO, P.; PELTONEN, J. Progress since the 1930s in breeding for yield, its components, and quality traits of spring wheat in Finland. Plant Breeding, Berlin, v.113, n.3, p.177-186, 1994.

RAMALHO, M. A. P.; SANTOS, J. B.;ZIMMERMANN, M. J. O. Genética quantitativa em plantas autógamas: aplicações ao melhoramento do feijoeiro. Goiânia: UFG, 1993.

RAUT, V. M.; TAWARE, S. P.; HALVANKAR, G. B.; PATIL, V.P. Stability analysis for oil and yield in soybean. Soybean Genetics Newsletter, Ames, v.24, p.92-93, 1997.

REIS, E. F.; REIS, M. S.; CRUZ, C. D.; SEDIYAMA, T. Comparação de procedimentos de seleção para produção de grãos em populações de soja. Ciência Rural, Santa Maria, v.34, n.3, p.685-692, 2004.

RIBEIRO, N. D.; POSSEBON, S. B.; STORCK, L. Progresso genético em caracteres agronômicos no melhoramento do feijoeiro. Ciência Rural, Santa Maria, v.33, n.4, p.629-633, 2003.

ROCHA, M. M.; VELLO, N. A. Interacão genótipos e locais para rendimento de grãos de linhagens de soja com diferentes ciclos de maturação. Bragantia, Campinas, v.58, n.1, p.69-81, 1999.

RODRIGUES, J. A. S. Progresso genético e potencial de risco da cultura do sorgo granifero (Sorghum bicolor (L.) Moench) no Brasil. 1990. (Doutorado)-Escola Superior de Agricultura “Luiz de Queiroz"/USP, Piracicaba. 
ROSSMANN, H. Estimativas de parâmetros genéticos e fenotípicos de uma população de soja avaliada em quatro anos. 2001. Dissertação (Mestrado em Agronômia)-Escola Superior de Agricultura "Luiz de Queiroz"/USP, Piracicaba.

SALADO-NAVARRO, L. R.; SINCLAIR, T. R.; HINSON, $\mathrm{K}$. Changes in yield and seed growth traits in soybean cultivars released in the Southern USA from 1945 to 1983. Crop Science, Madison, v.33, n.6, 1204-1209, 1993.

SOARES, A. A.; SANTOS, P. G.; MORAIS, O. P.; SOARES, P. C.; REIS, M. S.; SOUZA, M. A. Progresso genético obtido pelo melhoramento do arroz de sequeiro em 21 anos de pesquisa em Minas Gerais. Pesquisa Agropecuária Brasileira, Brasília, v.34, n.3, p.415-424, 1999.

SOLDINI, D. O. Interação genótipos x locais e correlações entre caracteres com ênfase na produtividade de óleo em soja. 1993. Dissertação (Mestrado em Genética e Melhoramento de Plantas)Escola Superior de Agricultura "Luiz de Queiroz"/USP, Piracicaba.

TOLEDO, J. F. F.; ALMEIDA, L. A.; KIIHL, R. A. S.; MENOSSO, M. G. Ganho genético em soja no Estado do Paraná, via melhoramento. Pesquisa Agropecuária Brasileira, Brasilia, v.25, p.89-94, 1990.
VENCOVSKY, R.; MORAES, A. R.; GARCIA, J. C.; TEIXEIRA, N. M. Progresso genético em vinte anos de melhoramento de milho no Brasil. Piracicaba: [s.n.], 1986.

VENCOVSKY, R.; MORAES, A. R.; GARCIA, J. C.; TEIXEIRA, N. M. Progresso genético em vinte anos de melhoramento do milho no Brasil. In: CONGRESSO NACIONAL DE MILHO E SORGO, 16., Belo Horizonte, 1986. Anais... Sete Lagoas: EMBRAPA/CNPMS, 1988. p.300-307.

VENCOVSKY, R.; BARRIGA, P. Genética biométrica no fitomelhoramento. Ribeirão Preto: Sociedade Brasileira de Genética, 1992.

WILCOX, J. R.; SCHAPAUGH JÚNIOR, W. T.; BERNARD, R. L.; COOPER, R. L.; FEHR, W. R.; NEIHAUS, M. H. Genetic improvement of soybeans in the Midwest. Crop Science, Madison, v.19, n.6, p.803-805, 1979.

WOODFIELD, D. R.; CARADUS, J. R. Genetic improvement in white clover representing six decades of plant breeding. Crop Science, Madison, v.34, n.5, p.12051213, 1994. 